\title{
Middle mediastinal thymoma
}

Kenji Kojima, MD, ${ }^{a}$ Kohei Yokoi, MD, ${ }^{a}$ Haruhisa Matsuguma, MD, ${ }^{a}$ Tetsuro Kondo, MD, ${ }^{\text {b }}$ Yukari Kamiyama, MD, ${ }^{\text {b }}$ Kiyoshi Mori, MD, ${ }^{\text {b }}$ and Seiji Igarashi, MD, ${ }^{\mathrm{c}}$ Tochigi, Japan

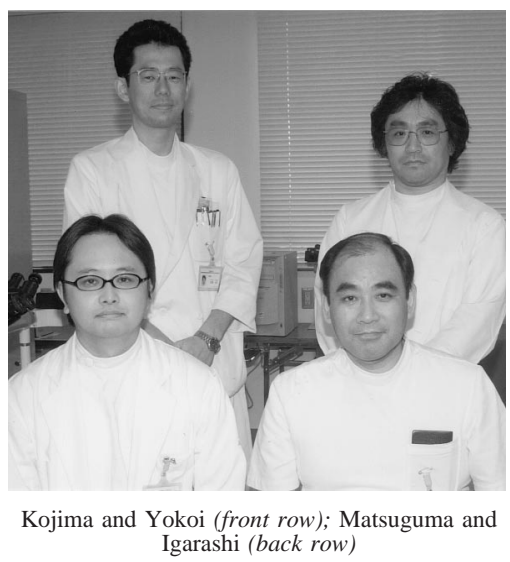

$\mathrm{T}$ he majority of thymomas are found in the anterior mediastinum. Occasionally, some have been found in the neck, pulmonary hilus, or posterior mediastinum. ${ }^{1}$ We present here a case of thymoma that developed entirely in the middle mediastinum, and the origin of this tumor is discussed. To our knowledge, a case of middle mediastinal thymoma including image findings has never been reported in the literature.

\section{Clinical Summary}

A 60-year-old woman was referred to our hospital with a mediastinal mass detected on plain chest $\mathrm{x}$-ray film during a medical check-up. Her past routine films were rechecked, and the mass could have been identified $7 \frac{1}{2}$ years earlier. However, the growth was very slow, and she had no clinical symptoms. Physical examination and laboratory work-up were within normal limits. Contrast-enhanced computed tomography showed a smooth, solitary, and nonhomogeneously enhanced mass measuring $5 \times 3 \times 3 \mathrm{~cm}$ in the middle mediastinum between the superior vena cava and trachea and did not have any calcification (Figure 1). On magnetic resonance imaging, the mass showed low signal intensity on a T1-weighted image and high signal intensity on a T2-weighted image, suggesting a cystic lesion. With a preliminary diagnosis of benign tumor, such as giant lymph node hyperplasia or neurogenic tumor, the patient underwent surgical intervention without preoperative pathologic or cytologic diagnosis.

Right thoracotomy demonstrated an extrapleural mass sandwiched between the superior vena cava and trachea and extended

From the Divisions of Thoracic Surgery, ${ }^{\mathrm{a}}$ Thoracic Diseases, ${ }^{\mathrm{b}}$ and Pathology, ${ }^{\mathrm{c}}$ Tochigi Cancer Center, Utsunomiya, Tochigi, Japan.

Received for publication March 11, 2002; accepted for publication March 24, 2002.

Address for reprints: Kohei Yokoi, MD, Division of Thoracic Surgery, Tochigi Cancer Center, 4-9-13 Yohnan, Utsunomiya, Tochigi 320-0834, Japan (E-mail: kyokoi@tcc.pref.tochigi.jp).

J Thorac Cardiovasc Surg 2002;124:639-40

Copyright @ 2002 by The American Association for Thoracic Surgery

$0022-5223 / 2002 \$ 35.00+0 \quad \mathbf{1 2 / 5 4 / 1 2 5 1 6 7}$

doi: $10.1067 / \mathrm{mtc} .2002 .125167$ from the azygos vein to below the right innominate artery. The tumor was solid and elastic with a fibrous capsule and easily extracted, except for dense adherence or connection to nerves. However, the upper part of the mass was observed to be contiguous to the adipose tissue surrounding the normal thymus at the area of the junction of bilateral brachiocephalic veins.

The resected specimen was a firm light-gray tumor with a smooth and fibrous capsule that measured $5.5 \times 3.5 \times 2.8 \mathrm{~cm}$ and weighed $40 \mathrm{~g}$. Many cysts of various sizes up to $12 \mathrm{~mm}$ in maximal diameter were observed on its cut surface. Neither hemorrhage nor necrosis was found. Microscopic examination demonstrated that in the major part of the tumor, spindle cells with round to oval nuclei were arranged in a whorled pattern, and small lymphocytes were scattered among them (Figure 2). In the minor part lymphocyterich, cortex-like areas were seen with sharp segregation from the area described above. Furthermore, the tumor cells had slightly invaded the adipose tissue adjacent to the capsule. These histopathologic findings were consistent with a diagnosis of predominantly spindle cell thymoma and type $\mathrm{AB}$ of the World Health Organization classification. ${ }^{2}$ The pathologic stage was stage II on the classification of Masaoka and colleagues, ${ }^{3}$ and the patient received postoperative radiotherapy of $50 \mathrm{~Gy}$.

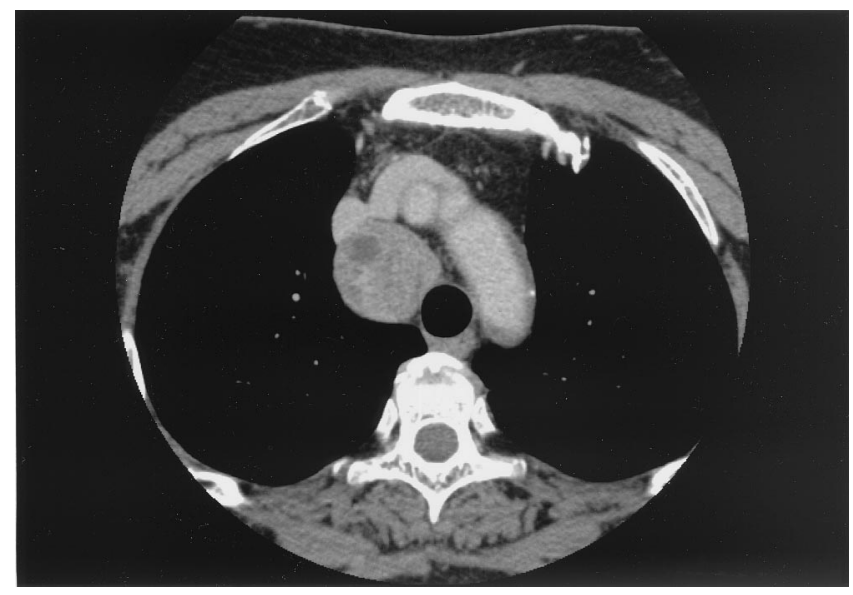

Figure 1. Enhanced computed tomographic scan showed a mass in the middle mediastinum between trachea and superior vena cava with nonhomogeneous enhancement. 


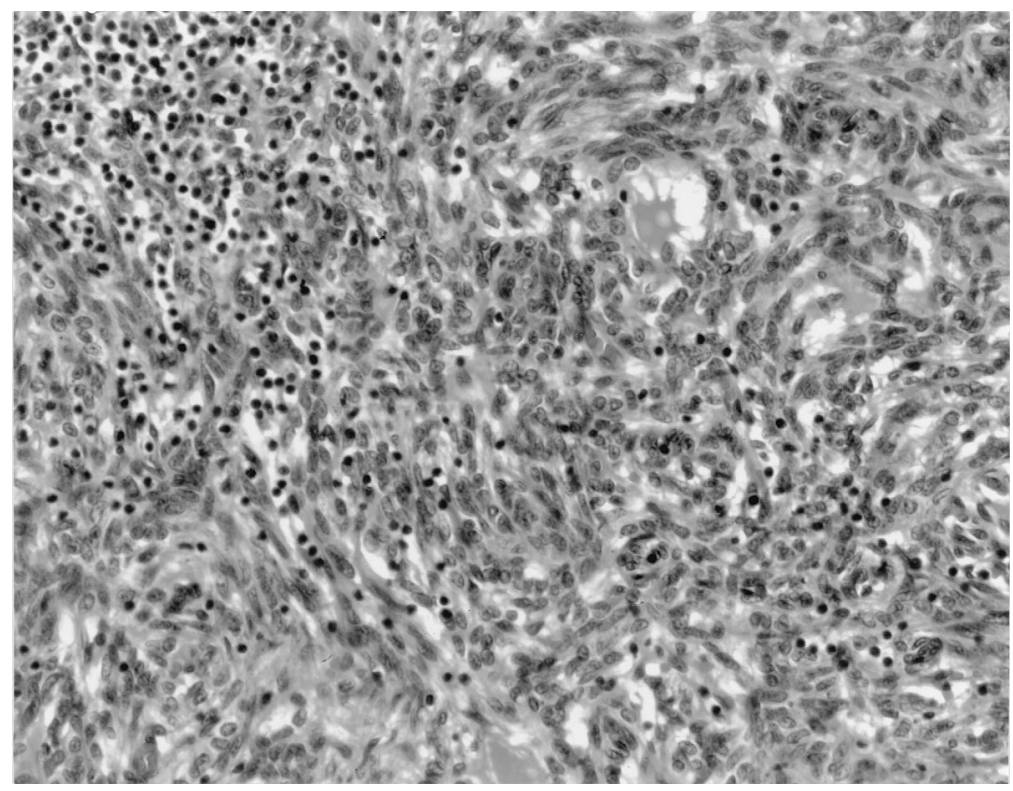

Figure 2. Histologic appearance of the tumor showed predominantly spindle cell thymoma (type AB). (Hematoxylin and eosin stain.)

\section{Discussion}

Corresponding to the location of the thymoma, the variations in thymoma sites quite faithfully reproduce the variations in the location of the normal thymus: $75 \%$ of the tumors are found in the anterior mediastinum, $15 \%$ in both the anterior and superior mediastinum, and $6 \%$ primarily within the superior mediastinum. The remaining $4 \%$ develop in the neck or posterior mediastinum. The rarest location is the posterior mediastinum. ${ }^{4}$ These rare sites of thymoma have previously been reported. However, to our knowledge, a detailed case report of middle mediastinal thymoma has not previously appeared in the literature.

Embryologically, thymic epithelium arises bilaterally from the third and probably fourth bronchial pouches and migrates into the anterosuperior mediastinum. Ectopic occurrence of thymoma results from failure of this migration. ${ }^{1}$

Ectopic thymomas are considered to arise from distributed thymic tissues, the existence of which has been proved. ${ }^{5,6}$ According to a current study, ectopic thymic tissue exists in a retroinnominate vein area, ${ }^{7}$ and adipose tissue surrounding the thymus, which occasionally contains some thymic tissue, often has continuity with pleural or hilar adipose tissue. ${ }^{5}$ These facts make it possible for thymomas to be located in the middle mediastinum, as in our case. The surgical findings in our case showed that the tumor was contiguous to the adipose tissue surrounding the thymus, suggesting that the tumor had originated from the ectopic thymic tissue behind the brachiocephalic veins and had become swollen and sagged over years of progression.
In the differential diagnosis of middle mediastinal masses, thymoma is not frequently considered. However, because of its malignant potential and a $96 \% 10$-year survival after complete macroscopic resection, ${ }^{8}$ thymoma should always be considered in the differential diagnosis of middle mediastinal tumors, and complete resection should be attempted at the time of the operation.

\section{References}

1. Shimosato Y, Mukai K. Tumors of the thymus and related lesions. In: Rosai J, editor. Atlas of tumor pathology. Fascicle 21, 3rd series. Washington: Armed Forces Institute of Pathology; 1995. p. 33-247.

2. Rosai J. Epithelial tumors. Histological typing of tumors of the thymus. 2nd ed. New York: Springer; 1999. p. 9-15.

3. Masaoka A, Monden Y, Nakahara K, Tanioka T. Follow-up study of thymomas with special reference to their clinical stages. Cancer. 1981;48:2485-92.

4. Rosai J, Levine GD. Tumors of the thymus. In: Fuminger HI, editor. Atlas of tumor pathology. Fascicle 13, 2nd series. Washington: Armed Forces Institute of Pathology; 1976. p. 34-161.

5. Masaoka A, Nagaoka Y, Kotake Y. Distribution of thymic tissue at the anterior mediastinum. Current procedures in thymectomy. J Thorac Cardiovasc Surg. 1975;70:747-54.

6. Fukai I, Funato Y, Mizuno T, Hashimoto T, Masaoka A. Distribution of thymic tissue in the mediastinal adipose tissue. J Thorac Cardiovasc Surg. 1991;101:1099-102.

7. Ashour M. Prevalence of ectopic thymic tissue in myasthenia gravis and its clinical significance. J Thorac Cardiovasc Surg. 1995;109: $632-5$

8. Moore KH, McKenzie PR, Kennedy CW, McCaughan BC. Thymoma: trends over time. Ann Thorac Surg. 2001;72:203-7. 